\title{
Pembinaan Wajib Pajak UMKM Orang Pribadi Dalam Pelaksanan PP 23 Tahun 2018 Di Wilayah Jakarta
}

\author{
Endro Andayani $^{\mathrm{a}, 1, *}$, Aji Prasetyo ${ }^{\mathrm{b}, 2}$, Muhammad. Yusuf ${ }^{\mathrm{b}, 3}$ \\ a,b Institut Ilmu Sosial dan Manajemen Stiami \\ 1 endroandayani@gmail.com* \\ * corresponding author
}

ARTICLE INFO

Article History

Received,30-01-2020

Revised,24-12-2020

Accepted,19-01-2021

Keywords

PKM UMKM;

$P P 23$ of 2018

ANNUAL SPT

\begin{abstract}
The socialization of PP 23 of 2018 which is an amendment to PP 46 of 2013 is very important to do because the socialization carried out by the government has not been carried out maximally so that still many UM KM Taxpayers (WP) have not clearly understood its implementation (Hendri, 2018). It is hoped that the guidance for UMKM Taxpayers (WP) whose turnover is less than 4.8 billion is expected to gain insight into what taxpayers can do related to the implementation of taxation and the responsibilities that must be carried out so that they are able to increase awareness to carry out their obligations which will then increase revenue. state revenue from the tax sector.

This socialization was carried out through Community Service activities (PKM). In this PKM activity, Taxpayers (WP) are given PP 23/2018 material, insight into the rights and obligations of Taxpayers (WP), provide motivation for compliance in carrying out tax obligations and training on how to calculate, pay, and report taxes with the e billing system and e filling.

The PKM results show an increase in knowledge about the implementation of PP 23/2018, new insights emerge that the procedures for calculating, paying and reporting taxes are carried out online so that it will simplify and speed up the process
\end{abstract}

\section{PENDAHULUAN}

\section{Latar Belakang}

Menurut laporan dari Direktorat Jenderal (Ditjen) Pajak, kenyataannya Pajak PPh final atas pajak yang diperoleh dari UMKM tahun sebelumnya belum mencapai target. Target dari jumlah Rp. 156, 18 triliun, diperoleh hanya Rp. 106,33 triliun atau 68,08 \%. Pencapaian ini menurun jika dilihat pada tahun 2016 diperoleh angka sebesar Rp117,68 triliun atau 80,77 \% ( Delapan Puluh koma Tujuh Puluh Tujuh Persen) (https://mucglobal.com/news/read/777/Genjot-Kepatuhan-Pajak-UMKM-Terus-Diburu). Keadaan ini membuat pemerintah harus lebih giat mengarahkan para pengusaha kecil dan menengah untuk menyetor kewajiban pajak, ternasuk pelaku ecommerce UMKM yang belum seluruhnya melaporkan Surat mberitahuanTahunan (SPT) Sebelumnya Direktorat Jenderal Pajak hanya fokus pada penagihan pajak pada Wajib pajak dalam usaha yang tergolong besar. Strategi ini nantinya dapat meningkatkan perolehan pajak serta menambah basis penagihannya.

Peraturan Pemerintah No 23 Tahun 2018 perihal pendapatan yang didapatkan dari kegiatan bisnis wajib pajak yang memiliki peredaran bruto dengan nilai tertentu yaitu Rp 4,8 Milyar dalam satu tahun masa pajak. Peraturan pemerintah ini berlaku mulai I I Juli 2018. Beberapa perubahan, antara lain tarif pajak penghasilan yang baru bagi PKM sebesar 0,5\% dari omset sebelumnya I \%. Peraturan tersebut sebagai pengganti PP No. 46 Tahun 2013. (Alfiatul Maulida, 2018)

Ada dua hambatan yang ada pada Wajib Pajak (W P) yaitu kesulitan menghitung pajak yang harus dibayar. Selain itu Wajib Pajak (WP) juga berkeinginan membayar pajak sekecil inungkin. Mereka inau mer ayar jika jumlahnya sudah sesuai keinginannya. Bila hal ini dibiarkan maka penghitungan pajak yang sudah terformulasi menjadi tidak sesuai. 
Dalam Perekonomian nasional di Indonesia, Usaha Mikro Kecil dan Menengah (UMKM) mempunyai peran cukup besar. Definisi UMKM Berdasarkan Undang- Undang Nomor 20 Tahun 2008,(Suci et al,2017) adalah sebagai berikut :

1. Usaha Mikro yaitu usaha produktif yang dimiliki orang perorangan dan/atau badan usaha perorangan yang memenuhi kriteria Usaha Mikro sesuai dengan Undang-Undang ini.

2. Usaha Kecil yaitu usaha ekonomi produktif yang berdiri sendiri, dilakukan oleh orang perorangan atau badan usaha dengan ketentuan bukan merupakan anak perusahaan atau bukan cabang perusahaan yang dimiliki, dikuasai, atau menjadi bagian baik langsung maupun tidak langsung dari Usaha Menengah atau Usaha Besar yang memenuhi kriteria Usaha Kecil sesuai dengan Undang-Undang ini.

3. Usaha Menengah yaitu suatu usaha ekonomi produktif yang berdiri sendiri, yang dijalankan oleh orang perorangan atau badan usaha yang bukan merupakan anak perusahaan atau cabang perusahaan yang dimiliki, dikuasai, atau menjadi bagian baik langsung maupun tidak langsung dengan Usaha Kecil atau Usaha Besar dengan jumlah kekayaan bersih atau hasil penjualan tahunan sesuai dengan Undang- Undang ini.

4. Usaha Besar adalah usaha ekonomi produktif yang dijalankan badan usaha dengan ketentuan jumlah kekayaan bersih atau hasil penjualan tahunan lebih besar dari Usaha Menengah, yang meliputi usaha nasional milik negara atau swasta, usaha patungan, dan usaha asing yang melakukan kegiatan ekonomi di Indonesia.

5. Dunia Usaha yaitu mencakup seluruh Usaha Mikro, Usaha Kecil, Usaha Menengah, dan Usaha Besar yang menjalankan kegiatan ekonomi di Indonesia dan bertempat tinggal di Indonesia.

Sedangkan Kriteria UMKM adalah sebagai berikut (Rahmadhani et al., 2020)

a. Usaha Mikro adalah usaha produktif yang dimiliki oleh orang perorangan dan/atau badan usaha perorangan dengan kriteria usaha mikro yang diatur berdasarkan undang-undang yaitu mempunyai kekayaan bersih paling tinggi sebesar Rp50.000.000,00 (lima puluh juta rupiah), tanah dan bangunan tempat usaha tidak masuk ; atau memiliki hasil penjualan tahunan paling tinggi sebesar Rp300.000.000,00 (tiga ratus juta rupiah).

b. Usaha Kecil adalah usaha ekonomi produktif yang berdiri sendiri, dilaksanakan oleh orang perorangan atau badan usaha yang bukan anak perusahaan atau bukan cabang perusahaan yang dimiliki, dikuasai, atau menjadi bagian baik langsung dari perusahaan atau bukan cabang perusahaan yang dirniliki, dikuasai, atau menjadi bagian baik langsung maupun tidak langsung dari usaha menengah dalam undang-undang yaitu memiliki kekayaan bersih lebih dari Rp50.000.000 (lima puluh juta rupiah) sampai dengan paling banyak Rp500.000.000 (lima ratus juta nipiah) dengan catatan tanah dan bangunan tempat usaha tidak termasuk ; atau memiliki hasil penjualan tahunan sebesar lebih dari Rp300.000.000 (tiga ratus juta rupiah) sampai dengan paling tinggi sebesar Rp2.500.000.000 (dua milyar lima ratus juta rupiah).

c. Kriteria usaha menengah adalah usaha ekonomi produktif yang berdiri sendiri, yang dijalankan oleh orang perseorangan atau badan usaha yang bukan merupakan anak perusahaan atau cabang perusahaan yang dimiliki, dikuasai, atau menjadi bagian baik langsung maupun tidak langsung dengan Usaha Kecil atau usaha besar dengan dengan penjualan tahunan mencapai sebesar Rp 2.500.000.000 (Dua Milyard Lima Ratus Juta ) sampai dengan Rp 50.000.000.000(lima puluh Milyar) dan memiliki kekayaan bersih lebih besar dari Rp 500.000.000(lima ratus juta rupiah)

Untuk lebih meningkatkan pemenuhan kewajiban perpajakan secara sukarela serta meningkatkan keikutsertaan Wajib Pajak UMKM dalam berkontribusi terhadap penerimaan negara, Pemerintah telah menerbitkan PP no 23 Tahun 201S berlaku sejak 1 Juli 2018 sebagai pengganti PP no. 46 Tahun 2013 tentang pajak penghasilan atas penghasilan dari kegiatan bisnis yang diterima atau diperoleh Wajib Pajak (WP) dengan peredaran bruto tidak lebih dari 4,8 milyar. Perubahan peraturan pemerintah tersebut disamping tarif menjadi $0,5 \%$ juga perluasan subyek pajak dan kewajiban pembukuan yang dilakukan pembatasan. Maksud dilakukan perubahan tersebut agar UMKM lebih berkembang dan meningkatkan kepatu han. Dalam jangka panjang bisa untuk menarnbah modal dan ikut rnendorong perekonomian. 
Salah satu komunitas yang mewadahi Wajib Pajak (WP) UMKM adalah Komunitas UMKM Bolu (Belajar Jualan Online Yuk). Beberapa permasalahan yang ada di Komunitas Bolu sebagai berikut yaitu

a. Pengetahuan tentang Ketentuan Umum Perpajakan (KUP) masih belum mengerti dan memahamidan dipahami.

b. Dalam penerapan PP No 23 Tahun 2018, masih belum di mengerti karena masih baru.

c. Kurangnya pengetahuan para pelaku usaha kecil mengenai cara mencatat transaksi keuangan

d. Dalam menghitung jumlah pajak yang harus dibayar dan membuat laporan pajak belum mengerti

Berdasarkan hal tersebut di atas, kami hadir untuk melaksanakan tri dharma perguruan tinggi, yaitu pengabdian kepada masyarakat dengan materi dengan cara memberikan materi PP 23 Tahun 2018 wawasan tentang hak- kewajiban Wajib Pajak (WP), memberikan motisvasi atas kepatuhan dalam melaksanakan kewajiban pajak dan pelatihan tata cara menghitung, membayar, dan melaporkan pajak dengan sistem e billing dan e filling pada UMKM di Komunitas Bolu Jakarta.

\section{Maksud Pelaksanaan Pengabdian Masyarakat}

a Menyampaikan materi kepada para pengusaha kecil di komnunitas Bolu tentang Ketentuan Umum Perpajakan.

b. Meningkat kan kemampuan bagi para pengusaha kecil di komunitas Bolu tentang pelaksanaan pp No. 23 Tahun 2018.

c. Menyampaikan materi kepada peserta tentang pencatatan keuangan, menghitung jumlah pajak yang dibayar dan melaporkan .

\section{Pengabdian Kepada Masyarakat (PKM) kepada UMKM ini agar:}

a. Mengetahui tentang KUP Perpajakan.

b. Mengetahui tentang PP 28 Tahun 2018 sebagai pengganti PP 46 Tahun 2018

c. Mengetahui mengenai pencatatan keuangan, menghitung besarya pajak yang akan disetorkan ke kas negara dan mengisi SPT

\section{PELAKSANAAN DAN METODE}

Sesuai dengan tujuan yang telah ditetapkan sebelumnya yaitu sasaran kegiatan ini adalah para pelaku usaha kecil/UMKM yang bergerak dibidang usaha kecil yang berada di kornunitas Bolu yang beranggotakan lebih dari 1000 pengusaha UMKM. Sampel yang diambil 10 pengusaha. Dalam pelaksanaan pengabdian kepada masyarakat dilakukan tahap-tahap (Majelis et al., 2020)sebagai berikut :

a. Berdiskusi dengan Co-founder Komunitas Bolu untuk mengidentifikasi inasalah yang terjadi di Komunitas Bolu agar mernudahkan kami dalam menyusun materi yang dibutuhkan sebagai survey awal.

b. Mengundang Wajib Pajak (WP) yang ditunjuk untuk mengikuti pelatihan sebagai penetapan sasaran

c. Membuat materi untuk sosialisasi pajak

d. Pelaksanaan pengabdian dengan ceramah materi pelatihan yang terdiri dari:

1. Pengertian pajak dan arti pentingnya pajak bagi pengusaha kecil UMKM

2. Kegiatan. Sosialisasi tentang PP Nomor 23 Tahun 2018 tentang pajak penghasilan atas penghasilan dari usaha yang diterima atau diperoleh Wajib Pajak (WP) yang memiliki peredaran bruto tertentu.

3. Membuat pencatatan keuangan

4. Menghitung besarnya pajak yang harus dibayar

5. Membuat pelaporan pajak

6. Sistem pembayaran dan pelaporan secara on line

e. Diskusi terkait dengan permasalahan-permasalahan pajak yang ada di lapangan

f. Pelatihan dan praktik peserta pelatihan diberi soal kasus untuk mencoba membuat pencatatan keuangan, menghitung besamya pajak yang harus dibayar serta membuat pela \}xiran pajak. 


\section{HASIL DAN PEMBAHASAN}

\section{Hasil}

\section{Bentuk Kegiatan, Waktu dan Tempat Kegiatan}

a. Pelaksanaan kegiatan pengabdian ini dikeinas dalarn bentuk pelatihan, pada tanggal 16 Maret 2019, di Kampus Institute STIAMl Jl Pangkalan Asem no 55 Cempaka Putih, JakanaPusat.Jadwal pelaksanaan sosialisasi sebagai berikut :

Tabel 1: Jadwal pelaksanan sosialisasi

\begin{tabular}{|l|l|l|l|}
\hline No & Waktu & Kegiatan & Pelaksana \\
\hline 1 & $08.00-09.00$ & Registrasi Peserta & Panitia \\
\hline 2 & $09.00-09.15$ & Pembukaan & Aji Prasetyo.SE .M.AK, CA \\
\hline 3 & $09.15-09.30$ & $\begin{array}{l}\text { Sambutan Perwakilan } \\
\text { Team PkM }\end{array}$ & Endro Andayani, SE.M Ak \\
\hline 4 & $09.30-09.45$ & $\begin{array}{l}\text { Sambutan CoFounder } \\
\text { Komunitas Bolu }\end{array}$ & Sandi Pratama \\
\hline 5. & $09.45-11.00$ & Materi 1 & Endro Andayani, SE.Ak \\
\hline 6 & $11.00-14.45$ & Materi 2 dan Istirahat & Muhammad Yusuf ,SE MAk \\
\hline 7 & $14.45-15.45$ & Tanya Jawab & Adji Prasetyo, SE.Mak CA \\
\hline 8 & $15.45-16.00$ & Penutupan & Adji Prasetyo, SE.Mak CA \\
\hline
\end{tabular}

b. Gambar / Foto Kegiatan

c.

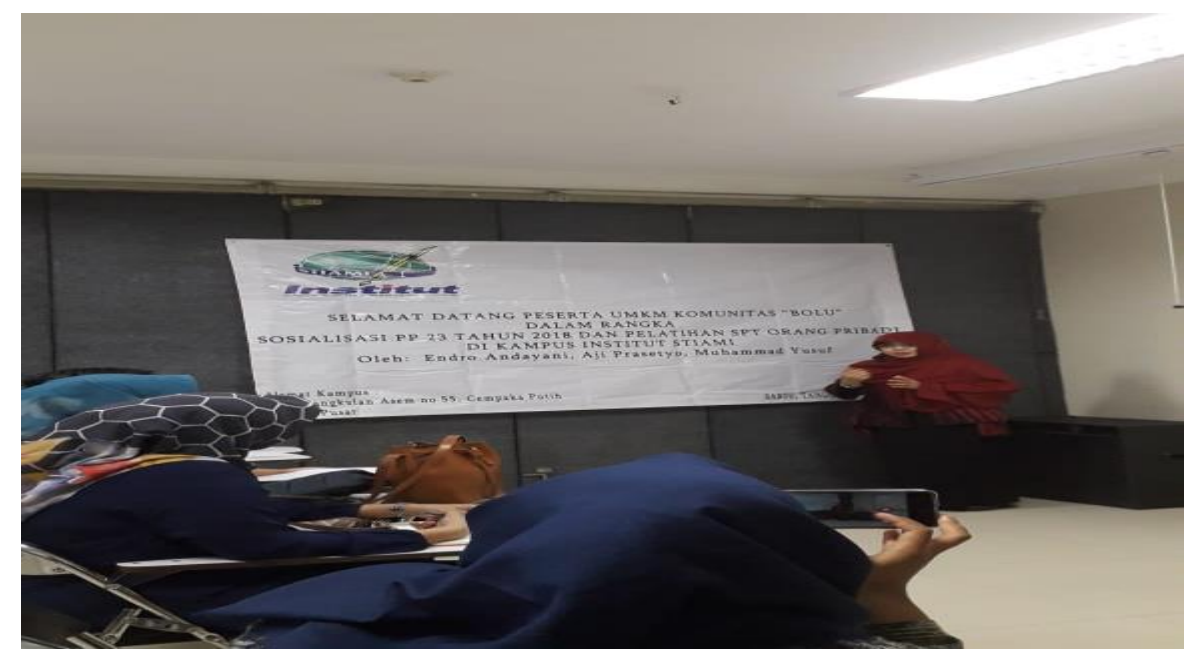

Gambar 1 Penyampaian Materi KUP

Dalam sosialisasi ini sebagai moderator Aji Prasetyo SE, M. Ak CA, sedangkan materi 1 pelatihan mengenai Ketentuan Umum Perpajakan (KUP). 


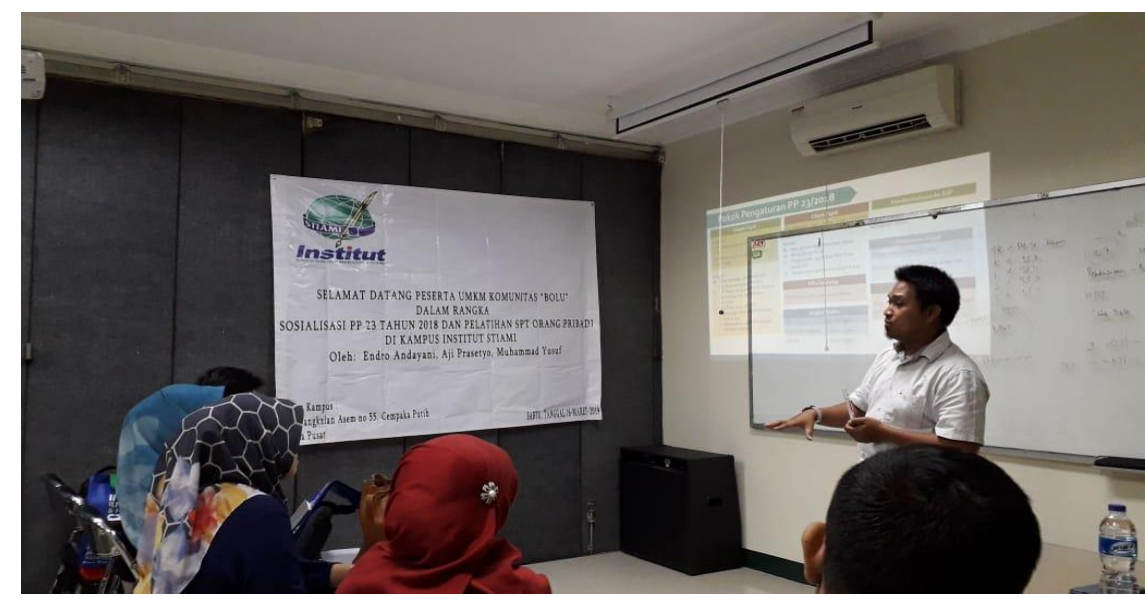

Gambar 2 Penyampaian Materi PP Nomor 23 Tahun 2018

Pada sosialisasi tentang PP nomor 23 Tahun 2018 tentang pajak penghasilan atas penghasilan dari usaha yang diterima atau diperoleh Wajib Pajak (WP) yang memiliki peredaran bruto tertentu, membuat pencatatan keuangan, menghitung besarnya pajak yang harus dibayar dan membuat pelaporan pajak disampaikan oleh M Yusuf SE, M.Ak

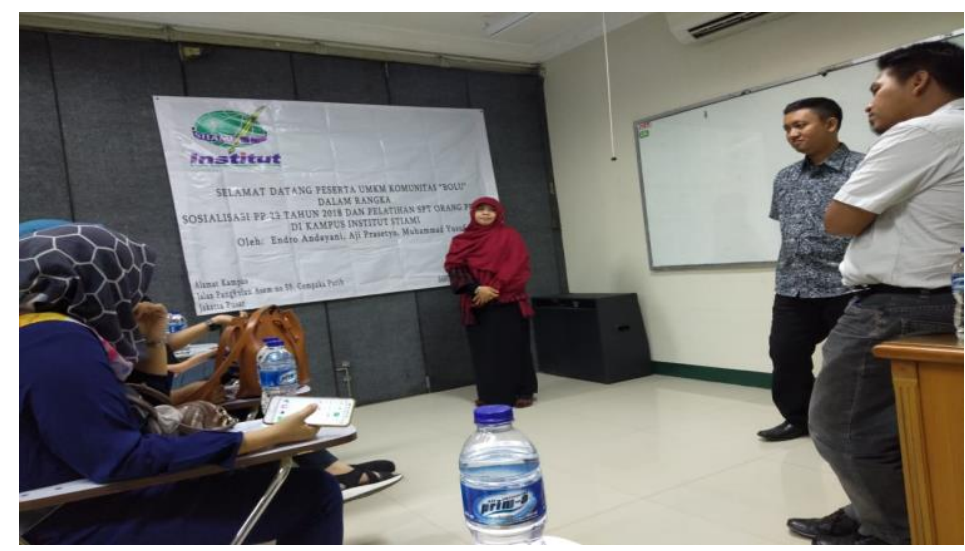

Gambar 3 Kegiatan Diskusi

Acara tanya jawab terkait dengan masalah pajak yang ada di lapangan dan praktik peserta pelatihan diberi soal kasus untuk menconba membuat pencatatan keuangan, menghitung besarnya pajak yang harus dibayar serta membuat pelaporan pajak dikoordinasi oleh Aji Prasetyo,SE.MAk CA sebagai moderator.

\section{d. Materi}

\section{-Kewajiban ber NPWP}

-Sanksi dministrasi

-Tarif PPh Final UMKM resmi turun dari $1 \%$ menjadi 0,5 \%, perubahan tarif PPh Final UMKM tersebut tercantum dalam PP No. 23 Tahun 2018, perubahan tarif yang efektif diberlakukan mulai 1 Juli 2018 .

-Tarif PPh Final 0,5\% bersifat pilihan karena wajib pajak dapat rnemilih untuk mengikuti tarif dengan skema final $0,5 \%$ atau menggunakan skema normal yang mengacu pada pasal $17 \mathrm{U}$ ndangkI ndang Nomor 36 Tahun 2005 tentang Pajak PPh.

-Pengenaan Tarif PPh Final 0,5\% punya batas waktu tidak seperti PP No. 46 Tahun 2013, kebijakan terbaru tentang PPh Final 0,5\%Ze punya grace period alias batasan waktu. Batasan waktu yang diberikan pemerintah bagi WP yang ingin menggunakan tarif PPh Final 0,5\% adalah

1) 7 (tujuh) tahun pajak bagi WP orang pribadi.

2) 4 (empat) tahun pajak bagi WP badan (koperasi, CV atau firma). 
3) 3 (tiga) tahun pajak bagi WP badan berbentuk PT.

Setelah batas waktu tersebut berakhir, WP akan kembali menggunakan skerna normal seperti diatur oleh pasal 17 UU No.36. Hal ini ditujukan untuk mendorong wajib pajak menyelenggarakan pembukuan dan pengembangan bisnisnya

-WP yang dikenai PPh final berpenghasilan dibawah Rp 4,8 M

- Siapa yang dapat memanfaatkan PPh Final 0,5\%

Wajib pajak yang memiliki peredaran bruto tertentu yang dikenai PPh Final 0,5\% adalah :

1. Wajib Pajak (WP) orang pribadi

2. Wajib Pajak (WP) badan berbentuk koperasi, CV, firma atau PT yang menerima atau rnernperoleh penghasilan dengan peredaran bruto dibawah $\mathrm{Rp}$ 4,8 miliar.

Wajib Pajak yang tidak dapat rnemanfaatkan fasilatas PPh Final 0,5\% adalah:

1. Wajib Pajak (WP) orang pribadi dengan pendapatan dari jasa yang terkait dengan pekerjaan bebas. Catatan hal ini juga berlaku untuk persekutuan atau firma yang terdiri dari WP orang pribadi berkeahlian sejenis seperti firma hukum, kantor akuntan dan lain sebagainya.

2. Wajib pajak dengan pendapatan pajak terutang dari luar negeri atau telah dibayar di luar negeri.

3. Wajib pajak dengan pendapatan telah dikenai PPh final .

4. Wajib pajak dengan pendapatan tidak termasuk objek pajak.

- Bayar PPh Final 0,5 \% lebih mudah melalui PajakPay

Mekanisme pembayaran PPh ke kas negara, dengan dating ke kantor pos/bank perspesi termasuk segala fasilitas yang disediakan oleh lembaga tersebut seperti ATM. Namun, bagi wajib pajak yang ingin mnenghemat waktu dan upaya untuk membayar pajak, bisa membayar pajak melalui Pajak Pay.

- Jika ingin mengikuti tarif skema normal, Wajib Pajak (WP) perlu mengajukan diri

- Tanya-jawab

- Praktek pengisian SPT

- Sistem On Line

\section{Pembahasan}

Hasil pelaksanaan pengabdian kepada masyarakat di Kornunitas Bolu dengan judul "Pembinaan Wajib Pajak UMKM Orang Pribadi Dalam Pelaksanaan PP 23 Tahun 2105 di W ilayah Jakarta" adalah sebagai berikut

a. Peserta pelatihan dapat memahami dan mengerti ketentuan umum perpajakan dan PP 23 Tahun 2018 untuk meningkatkan kesadaran Wajib Pajak (WP) agar patuh.

b. Peserta memahami proses pembayaran dan pelaporan secara on line

c. Peserta mengerti dan mempraktikan proses menghitung, membayar dan melapor SPT Tahunan .

Sesuai dengan penelitian yang dilakukan oleh (Wardani \& Wati, 2018) bahwa sosialisasi dan pengetahuan pajak berpengaruh terhadap kepatuhan Wajib Pajak sehingga di harapkan dapat menambah penerimaan negara

\section{PENUTUP}

\section{Simpulan}

Kegiatan Pengabdian Kepada Masyarakat (PKM) bertujuan meningkatkan kesadaran kepada Wajib Pajak (W P) di Komunitas Bolu tentang arti pentingnya pajak bagi pembangunan bangsa Indonesia, meningkatkan pengetahuan, ketrampilan dan pencatatan keuangan dalam kegiatan usaha, sehingga mengetahui bahwa kewajiban bagi yang melakukan usaha harus terlebih dahulu mengajukan permohonan untuk NPWP, menyetor dan melapor kan pajak penghasilan dengan jujur berdasarkan ketentuan peraturan peundang-undangan yaitu PP no 23 . Metode pelaksanaan dengan sosialisasi kepada beberapa peserta sebagai perwakilan. Selama acara tersebut peserta antusiasme, hal ini ditunjukan keaktifan peserta saat acara diskusi atas permasalahn yang dihadapi.

\section{Saran}

Untuk selanjutnya tetap dilakukan sosialisasi dengan perwakilan peserta untuk bidang usaha yang berbeda 


\section{DAFTAR PUSTAKA}

Hendri. (2018). Implementasi Sosialisasi Peraturan Pemerintah No. 23 Tahun 2018 Bagi Pelaku Usaha Mikro, Kecil Dan Menengah (UMKM). Jurnal Vokasi Indonesia, 6(2), 53-58. https://doi.org/10.7454/jvi.v6i2.127

Majelis, D. I., Wah, D. A., \& Adni, A. L. (2020). Pelatihan Perpajakan Untuk UMKM. 1.

Rahmadhani, S. R., Cheisviyanny, C., \& Mulyani, E. (2020). Analisis kepatuhan pajak pelaku umkm pasca penerbitan peraturan pemerintah nomor 23 tahun 2018. ISSN : 2656-3649, Vol. 2, No 1, Seri E, Februari 2020, 2(1), 2537-2553.

Suci, Y. R., Tinggi, S., \& Ekonomi, I. (2017). Perkembangan UMKM (Usaha Mikro Kecil Menengah) di Indonesia. Jurnal Ilmiah Fakultasi Ekonomi, 6(1), 51-58.

Wardani, D. K., \& Wati, E. (2018). Pengaruh Sosialisasi Perpajakan Terhadap Kepatuhan Wajib Pajak Dengan Pengetahuan Perpajakan Sebagai Variabel Intervening (Studi Pada Wajib Pajak Orang Pribadi di KPP Pratama Kebumen). Nominal, Barometer Riset Akuntansi Dan Manajemen, 7(1). https://doi.org/10.21831/nominal.v7i1.19358

\section{Buku}

Mardiasrno (2018). Perpajakan. Edisi Revisi. Yogyakarta : ANDl

Waluyo (2017), Perpajakan Indonesia. Jakarta: Salemba Empat.

\section{UU dan Peraturan Pemerintah}

Undang-Undang (UU) No.16 Tahun 2009 mengenai perubahan ke empat Ketentuan Umum dan Tata Cara Perpajakan (KUP)

Undang-Undang Republik Indonesia Nomor 20 Tahun 2008 Tentang Usaha Mikro, Kecil, dan Menengah

PP Nomor 23/2018 tentang Kebijakan Perpajakan UMKM

\section{Sumber lainnya}

https://mucglobal.com/news/read/777/Genjot-Kepatuhan-Pajak--UMKM-Terus-Diburu 